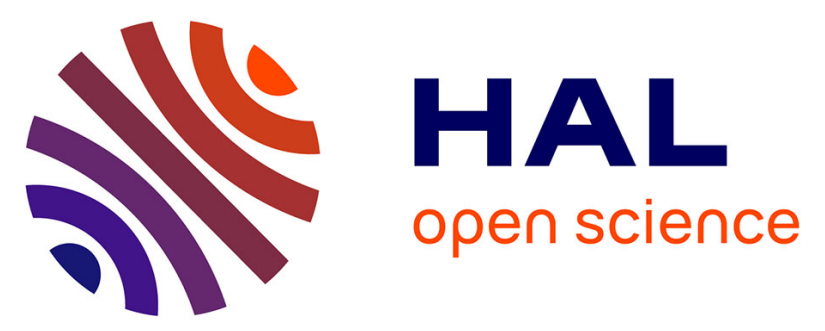

\title{
Nonionic organoclay: A 'Swiss Army knife' for the adsorption of organic micro-pollutants?
}

Régis Guégan, Marcelo Giovanela, Fabienne Warmont, Mikael Motelica-Heino

\section{To cite this version:}

Régis Guégan, Marcelo Giovanela, Fabienne Warmont, Mikael Motelica-Heino. Nonionic organoclay: A 'Swiss Army knife' for the adsorption of organic micro-pollutants?. Journal of Colloid and Interface Science, 2015, 437, pp.71 - 79. 10.1016/j.jcis.2014.09.043 . insu-01088187

\section{HAL Id: insu-01088187 https://hal-insu.archives-ouvertes.fr/insu-01088187}

Submitted on 27 Nov 2014

HAL is a multi-disciplinary open access archive for the deposit and dissemination of scientific research documents, whether they are published or not. The documents may come from teaching and research institutions in France or abroad, or from public or private research centers.
L'archive ouverte pluridisciplinaire HAL, est destinée au dépôt et à la diffusion de documents scientifiques de niveau recherche, publiés ou non, émanant des établissements d'enseignement et de recherche français ou étrangers, des laboratoires publics ou privés. 
Nonionic organoclay: A 'Swiss Army knife' for the adsorption of organic micro-pollutants?

Régis Guégan ${ }^{1,{ }^{*},}$, Marcelo Giovanela ${ }^{2}$, Fabienne Warmont $^{3}$, Mikael Motelica-Heino $^{l}$

${ }^{1}$ Institut des Sciences de la Terre d'Orléans, UMR 7327, CNRS-Université d'Orléans, 1A Rue de la Férollerie, 45071 Orléans Cedex 2, France

${ }^{2}$ Centro de Ciências Exatas e Tecnologia, Universidade de Caxias do Sul, 95070-560 Caxias do Sul, RS, Brazil

${ }^{3}$ Centre de Recherche de la Matière Divisée, FRE3520, CNRS-Université d'Orléans, 1B Rue de la Férollerie, 45071 Orléans Cedex 2, France

regis.guegan@univ-orleans.fr

mgiovan1@ucs.br

fabienne.warmont@.cnrs-orleans.fr

mikael.motelica@univ-orleans.fr

August 05 $^{\text {th }}, 2014$

*To whom correspondence should be addressed. E-mail: regis.guegan@univ-orleans.fr. Phone: +33 (0) 2384925 41. Fax: +33 (0) 238636488

\begin{abstract}
A Na exchanged montmorillonite (Mt) was used as a starting layered material for the preparation of two organoclays synthesized with benzyl decyltrimethyl ammonium (BDTA) cationic surfactant and the tri-ethylene glycol mono n-decyl ether $\left(\mathrm{C}_{10} \mathrm{E}_{3}\right)$, a nonconventional nonionic surfactant. The adsorption of the surfactants was performed at an amount of 0.7 times the cation exchange capacity (CEC) for BDTA and below the critical micelle concentration $(\mathrm{cmc})$ where $\mathrm{C}_{10} \mathrm{E}_{3}$ is in a monomer state, leading to the intercalation of a lateral monolayer surfactant arrangement within the interlayer space and about 5-7\% organic carbon content in organoclays. The environmental properties of both nonionic $\left(\mathrm{C}_{10} \mathrm{E}_{3}-\mathrm{Mt}\right)$ and cationic (BDTA-Mt) organoclays were compared to those of the starting Mt clay with the sorption of three micro-pollutants: benzene, dimethyl-phthalate and paraquat. The adsorption isotherms and the derivative data determined through the fitting procedure by using Langmuir, Freundlich and DubininRadushkevitch equation models explicitly highlighted the importance of the chemical nature of the
\end{abstract}


micropollutants, which play on the adsorbents efficiency. The adsorption data combined with FTIR and XRD supplementary results suggest that $\mathrm{C}_{10} \mathrm{E}_{3}-\mathrm{Mt}$ nonionic organoclay, although being less efficient for the retention of the different micropollutants, turned out to be the most polyvalent adsorbent since such hybrid material could sequestrate the entire studied organic compounds.

\section{Introduction}

The anthropogenic input organic micro-pollutants hydro-systems generates severe human health risks and impacts on aquatic ecosystems [1]. Despite the establishment of strict regulations on industrial discharges and the improvement of specific treatments for both wastewater and drinking water, numerous organic products, incriminated to be responsible of several cancers, are accumulated at significant concentrations in the water [2,3].

Clay minerals have been for a long time known for their outstanding adsorption properties. However, although being used in drinking water treatment, these layered materials turned out to be ineffective for the sequestration of persistent nonpolar hydrophobic contaminants [4-10]. The intercalation of cationic surfactants, through ion exchange with the inorganic cations, switches the chemical nature of the starting layered material from hydrophilic to hydrophobic. Moreover, the resulting organoclay composite has a wide opening of its interlayer space that significantly improve the adsorption of numerous organic compounds [4-10]. Nevertheless, the improvement of the sequestration mainly depends on both the chemical nature and the structural organization of the intercalated surfactants. Thus, surfactants showing a long alkyl chains such as hexadecyltrimethylammonium (HDTMA) create an appropriate organic environment within the inorganic frame for the adsorption of alkanes whereas modifiers such as benzyl decyltrimethylammonium (BDTA) show an excellent affinity with aromatic compounds [10].

While numerous works focused on the improvement of the sequestration of organic contaminants by using cationic organoclays, the study on the adsorption properties of organoclays synthesized with unconventional nonionic surfactants showed far much less interest which is even more surprising in 
regards to the major interests that nonionic surfactants show: (i) a biodegradability and a no toxicity [11]; (ii) a good thermal and chemical stabilities [12,13]; (iii) a preservation of the exchangeable inorganic cations after adsorption onto clay minerals, conferring a dual hydrophilic / hydrophobic character [14-18]; (iv) a still possible cation exchange of the resulting nonionic organoclay with both organic and inorganic cations [13,16,17,19]; and (v) aggregates of which structural arrangement depends on the surfactant state in aqueous solution expanding at wide openings the interlayer space of the layered material $[13,17,19]$.

Thus, this work focuses on the study of the adsorption properties of nonionic organoclay using the triethylene glycol mono n-decyl ether $\left(\mathrm{C}_{10} \mathrm{E}_{3}\right)$ and compare them to those of the starting clay mineral (Mt) and a cationic organoclay. The selected BDTA cationic surfactant combines a long alkyl chain and an aromatic ring of which affinity with organic compounds was shown in various works. It should be also noticed that in order to get realistic and economical viable organoclay materials, only a monolayer of surfactant was confined within the interlayer space of Mt. Such organoclay arrangement, where the surfactant undergoes severe effects of confinement, shows a maximal thermal stability and prevents any unwanted surfactant release. The adsorption properties of the three sorbent materials were studied by focusing on three water micro-pollutants: (i) benzene; (ii) dimethyl phthalate; and (iii) paraquat,. If the adsorption of benzene and paraquat on both clay minerals and cationic organoclays has been the subject of numerous studies focusing on the behavior of the adsorption isotherms, details on the evolution of the interlayer space determined by XRD and FTIR analyses are still scarce. Moreover, no study has been focused on the sequestration of these two pollutants by a nonionic organoclay as well as the adsorption of phthalate. Results obtained in this study with the use of a set of complementary techniques (XRD, FTIR, and adsorption isotherms), beyond serving as only data for the effectiveness comparison of the three different sorbents will be useful to identify the interactional mechanisms involved in the adsorption of organic micro-pollutants. 


\section{Materials and Methods}

\subsection{Clay mineral}

Wyoming sodium montmorillonite (Mt), obtained from the Source Clay Minerals Repositery, University of Missouri (Columbia, MO) was used in this study as a starting material. This Mt clay mineral shows a cation exchange capacity (CEC) of 80 meq per $100 \mathrm{~g}$ clay, and a BET specific surface area of $35 \mathrm{~m}^{2} \cdot \mathrm{g}^{-1}$ (condensation of a non-polar $\mathrm{N}_{2}$ gas) as well as a $660 \mathrm{~m}^{2} \cdot \mathrm{g}^{-1}$ accessible surface area determined through the adsorption of ethylene glycol due to the solvation of $\mathrm{Na}^{+}$cations in Mt for polar molecules [21,22]. The Mt clay was fractioned to $<2 \mu \mathrm{m}$ by gravity sedimentation, purified and $\mathrm{Na}$ exchanged by well-established procedures [21].

\subsection{Experimental techniques}

The concentration of carbon in solution and on solids were measured using an elemental analyzer (Shimadzu TOC 5050 /SSM 5000-A). Moreover, the amounts of adsorbed organic compound and equilibrium isotherms were determined by using a Hitachi U-1900 UV spectrometer on the basis of the concentration decrease after both clay mineral and organoclays impregnation.

Fourier transform infrared (FTIR) measurements in the range $650-4000 \mathrm{~cm}^{-1}$, were recorded using a Thermo Nicolet 6700 FT spectrometer equipped with a Deuterated Triglycine Sulfate (DTGS) detector and a Nicolet Continu $\mu \mathrm{m}$ microscope. The powder samples were spread over a $\mathrm{NaCl}$ window of the microscope. The analyzed sample area was a square of side $100 \mu \mathrm{m}$ chosen under the microscope $15 \mathrm{X}$ Infinity Reflechromat objective. The analyses were performed in transmission mode and each spectrum was the average of 256 scans collected at $2 \mathrm{~cm}^{-1}$ resolution.

The $\mathrm{d}_{001}$ spacing's of the starting layered materials and after being in contact with organic pollutants were determined by the first $00 \mathrm{l}$ reflection from the X-rays patterns which were recorded in a conventional $\theta-\theta$ Bragg-Brentano configuration by using a Thermo Electron ARL'XTRA diffractometer equipped with a $\mathrm{Cu}$ anode $\left(\mathrm{CuK}_{\alpha 1,2}=1.5418 \AA\right)$ coupled with a $\mathrm{Si}(\mathrm{Li})$ solid detector. The 
diffractogramms on dry samples $\left(100^{\circ} \mathrm{C}\right.$ for 24 hours $)$ were performed between 1 and $62^{\circ}(2 \theta)$ with an angular and time steps of $0.04^{\circ}$ and 10 s respectively.

The morphology of both Na-Mt and organoclays was visualized by transmission electron microscopy (TEM) using a Philips CM20 microscope operating at $200 \mathrm{kV}$. The samples were initially dispersed in a $50 \%$ ethanol solution and then dropped on holey carbon grids and dried at $80^{\circ} \mathrm{C}$ before TEM observations.

\subsection{Organoclay preparation}

Tri-ethylene glycol mono n-decyl ether $\left(\mathrm{C}_{10} \mathrm{E}_{3}\right)$ nonionic surfactant, purchased from Nikko Chemicals, Inc., (Tokyo, Japan), and assumed to have a purity $>99.8 \%$ was used without any further purification. Benzyldimethyltetradecyl ammonium chloride (BDTAC) cationic surfactant was supplied from Sigma Aldrich. Aqueous solutions of BDTAC and $\mathrm{C}_{10} \mathrm{E}_{3}$ with Millipore deionized water were prepared at room temperature for concentrations at 0.7 times the cation exchange capacity (CEC) and 4.10 ${ }^{-4}$ mol. $\mathrm{L}^{-1}$ (below the cmc of $\mathrm{C}_{10} \mathrm{E}_{3}$ ) respectively. These surfactant solutions were poured in aqueous $\mathrm{Mt}$ dispersions and the solutions were stirred at $250 \mathrm{rpm}$ for 48 hours. After agitation, the solutions were centrifuged at $5500 \mathrm{rpm}$ for $30 \mathrm{~min}$ and the supernatants were removed. The resulting organoclays were washed with Millipore deionized water and centrifuged twice and dried at $100^{\circ} \mathrm{C}$ for 48 hours before FTIR and XRD analyses.

\subsection{Sorption of the micro-pollutants}

Benzene, dimethyl phthalate (dimethyl benzene-1,2-dicarboxylate) and paraquat (1,1'-dimethyl-4,4'bipyridylium chloride) were purchased from Sigma-Aldrich Chemical. Batch sorption isotherms were conducted in duplicate using at least 15 initial aqueous concentrations ranging from $5 \mathrm{mg} . \mathrm{L}^{-1}$ to 1 g.L. $\mathrm{L}^{-1}$ for the organic micro-pollutants: benzene, paraquat, and dimethyl-phthalate. All of these organic

compounds have aqueous solubility better than $1 \mathrm{~g} . \mathrm{L}^{-1}$. The aqueous solutions were added to the two 
organoclays and the starting clay mineral sorbents contained in $60 \mathrm{~mL}$ centrifuge tubes. Samples were shaken on a rotary shaker at $50 \mathrm{rpm}$ for $48 \mathrm{~h}$ in order to achieve the equilibrium of adsorption determined with preliminary tests, and then centrifuged at $5500 \mathrm{rpm}$ for $30 \mathrm{~min}$. Both supernatants and sorbents after contact with the pollutants were removed and analyzed through UV spectroscopy. The amount of adsorbed organic contaminants was calculated by the difference between the initial and equilibrium final concentrations that allowed us to determine the adsorption isotherms for the whole pollutants on the clay mineral and its organoclay derivatives. Before their XRD and FTIR characterizations, the entire resulting organoclays and Mt after adsorption of contaminants were dried at $100^{\circ} \mathrm{C}$ for 48 hours.

\subsection{Adsorption isotherm fitting procedure}

The resulting adsorption isotherms of the contaminants onto organoclays and Mt were fit using Langmuir model expressed as: ${ }^{23}$

$$
q_{e}=\frac{q_{\max } K_{L} C_{e}}{1+K_{L} C_{e}}
$$

Where $q_{\mathrm{e}}$ is the equilibrium paraquat amount adsorbed on sorbents (mol.g ${ }^{-1}$ ), $C_{\mathrm{e}}$ the equilibrium micropollutant concentration in the resulting solution $\left(\mathrm{mol}_{\mathrm{L}} \mathrm{L}^{-1}\right), q_{\max }$ the maximum adsorption capacity of the sorbents (mol.g $\left.{ }^{-1}\right)$ and $K_{\mathrm{L}}$ is the Langmuir adsorption constant (L.mol ${ }^{-1}$ ) which is related to the (2) free energy $\left(\Delta G^{\circ}\right)$ of adsorption by the relation (2):

$$
\Delta G^{\circ}=-R T \ln K_{\mathrm{L}}
$$

Since the adsorption of surfactant contributes to a change of the chemical nature of the surface as well as a heterogeneity in the distribution of the adsorption sites, a Freundlich and a Dubinin-Radushkevish (D-R) model isotherm equations were used. The Freundlich isotherm is an empirical equation to describe heterogeneous systems of which the linear form is: ${ }^{23,24}$

$$
\ln q_{\mathrm{e}}=\ln K_{\mathrm{F}}+\frac{1}{n} \ln C_{\mathrm{e}}
$$


where $K_{\mathrm{F}}\left(\mathrm{L}_{\mathrm{g}} \mathrm{g}^{-1}\right)$ and $n$ are Freundlich adsorption isotherm constants, being indicative of the extent of the adsorption and the degree of nonlinerarity between the solute concentration and adsorption respectively. The D-R isotherm represents a more general model for adsorption, since it assumes a heterogeneous surface and a variability for the adsorption potential and was applied successfully

for fitting the adsorption of organic species onto $\mathrm{Mt}^{24,25}$ The linear form of this latter model is written by the eq (4):

$$
\ln q_{\mathrm{e}}=\ln q_{\mathrm{m}}-\beta \varepsilon^{2}
$$

where $\beta$ is a constant related to the mean free energy of adsorption per mole of the sorbents $\left(\mathrm{mol}^{2} . \mathrm{J}^{-2}\right)$, $q_{\mathrm{m}}$, the theoretical saturation capacity and $\varepsilon$ corresponds to the Polanyi potential, which is equal to:

$$
\varepsilon=R T \ln \left(1+\frac{1}{C_{e}}\right)
$$

Where $R\left(\mathrm{~J} \cdot \mathrm{mol}^{-1} \cdot \mathrm{K}^{-1}\right)$ is the gas constant and $T(\mathrm{~K})$ is the absolute temperature. The constant $\beta$ provides the identification of the mean free energy $E\left(\mathrm{~kJ} \mathrm{~mol}^{-1}\right)$ of adsorption of organic compounds to sorbents surface and can be determined by using the relationship (6): ${ }^{25,26}$

$$
E=\frac{1}{\sqrt{2 \beta}}
$$

This latter parameter gives information whether the adsorption mechanism involves ion exchange or physical adsorption. Indeed, if the magnitude of $E$ is between 8 and $16 \mathrm{~kJ}^{\mathrm{mol}}{ }^{-1}$, the adsorption process follows an ion-exchange, while for $\mathrm{E}<8 \mathrm{~kJ} \cdot \mathrm{mol}^{-1}$ physisorption is envisaged. ${ }^{27}$ 


\section{Results and Discussion}

\subsection{Organoclays properties}

The $\mathrm{C}_{10} \mathrm{E}_{3}-\mathrm{Mt}$ and BDTA-Mt organoclays were characterized by XRD, TEM and FTIR analyses.

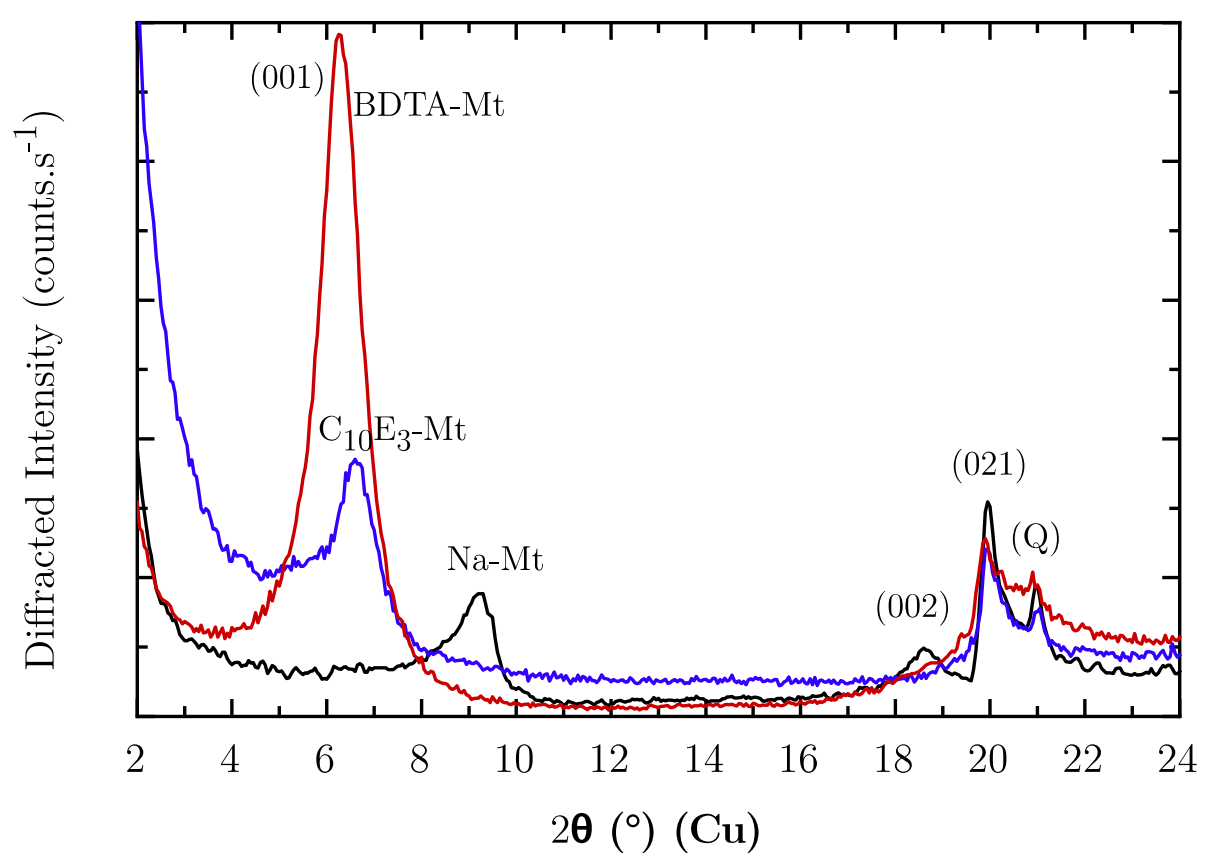

Figure 1: $\mathrm{X}$ ray diffraction patterns for untreated dehydrated Na-Mt (black solid line), dehydrated $\mathrm{C}_{10} \mathrm{E}_{3}-\mathrm{Mt}$ nonionic organoclay (blue solid line) and dehydrated BDTA-Mt cationic organoclay (red line). The (001) and (021) reflections of the layered materials are labeled. (Q) refers to the presence of quartz in the samples.

Both $00 \mathrm{l}$ diffraction patterns of the prepared organoclays shift to lower angular values underlining the expansion of the interlayer space at 14 and $13.5 \AA$ for dehydrated BDTA-Mt and $\mathrm{C}_{10} \mathrm{E}_{3}$-Mt respectively in contrast to $9.7 \AA$ for the untreated dehydrated Na-Mt (Figure 1). As expecting with the concentrations of the prepared surfactant solutions, where $\mathrm{C}_{10} \mathrm{E}_{3}$, below the cmc is only in monomers form, and for BDTA below 1 times the CEC, the adsorption leads to the intercalation of a lateral surfactant monolayer within the interlayer space $[13,18]$. Indeed, the intersheet separation in organoclay materials matches the height of both BDTA and $\mathrm{C}_{10} \mathrm{E}_{3}$ where surfactants lie parallel to the plane of the silicate layers. Transmission electron microscopy pictures confirm the proper intercalation of surfactant within the interlayer space of starting montmorillonite. In addition, TEM pictures give information on morphology of the organoclay systems where some area show regularly intercalated layers with regular layer-tolayer distance whereas other are display randomly intercalated layers suggesting an irregular 
intercalation with lower surfactant concentration (Figure 2). FTIR organoclays spectra show typical features characteristics of the organic compounds: the absorption bands at $2840-2920 \mathrm{~cm}^{-1}$ relative to the symmetric and antisymmetric $\mathrm{CH}_{2}$ stretching vibrations of the surfactant alkyl chains (Figure 3 ). It is well established that the wavenumber of the $\mathrm{CH}_{2}$ stretching bands of hydrocarbon chains are extremely sensitive to the conformational ordering and change in the gauche-trans conformer ratio of the chains which can be used as probe, in correlation with the $\mathrm{d}_{001}$ spacing variation, for the surfactant arrangement within the silicate layers. At such low surfactant concentration for the organoclay preparation, the wavenumber shift to high value (up to 5 and $12 \mathrm{~cm}^{-1}$ for symmetric and antisymmetric $\mathrm{CH}_{2}$ stretching vibrations) comparatively to bulk surfactant system (not shown) indicating a disordered monolayer structure in the interlayer space of Mt.
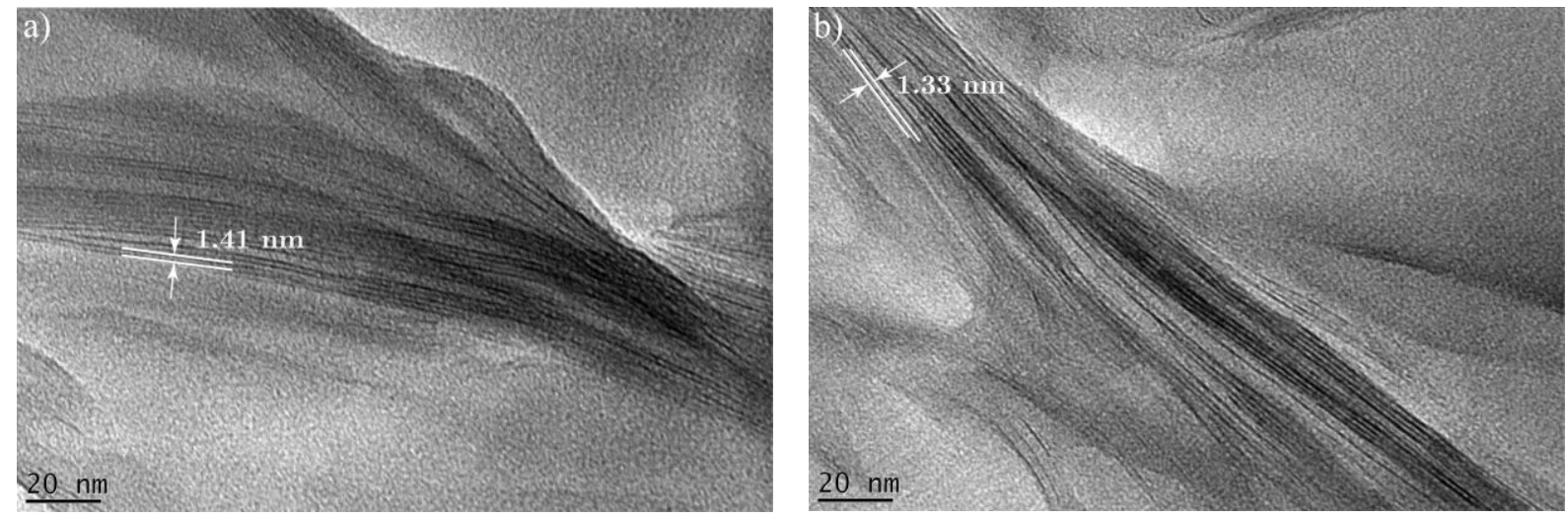

Figure 2: Transmission Electron Microscopy (TEM) images of a) BDTA-Mt orgonclay dispersed with 50\% ethanol solution and b) $\mathrm{C}_{10} \mathrm{E}_{3}-\mathrm{Mt}$ organoclay dispersed with $50 \%$ ethanol.

Despite such small loadings of surfactant, estimated through elementary analysis at 5.2 and $6.1 \%$ of organic content for $\mathrm{C}_{10} \mathrm{E}_{3}$ and BDTA respectively, the resulting organoclays exhibit a hydrophobic behavior. Indeed, such behavior is confirmed through the measure of the hydraulic conductivity for both organoclays, which is increased in contrast to raw Mt (results not shown here). Since, the adsorption of $\mathrm{C}_{10} \mathrm{E}_{3}$ keeps the whole $\mathrm{Na}^{+}$exchangeable cations, the prepared $\mathrm{C}_{10} \mathrm{E}_{3}-\mathrm{Mt}$ organoclay is assumed to show a dual hydrophilic/hydrophobic character, suitable for the adsorption of large range of organic contaminants. 


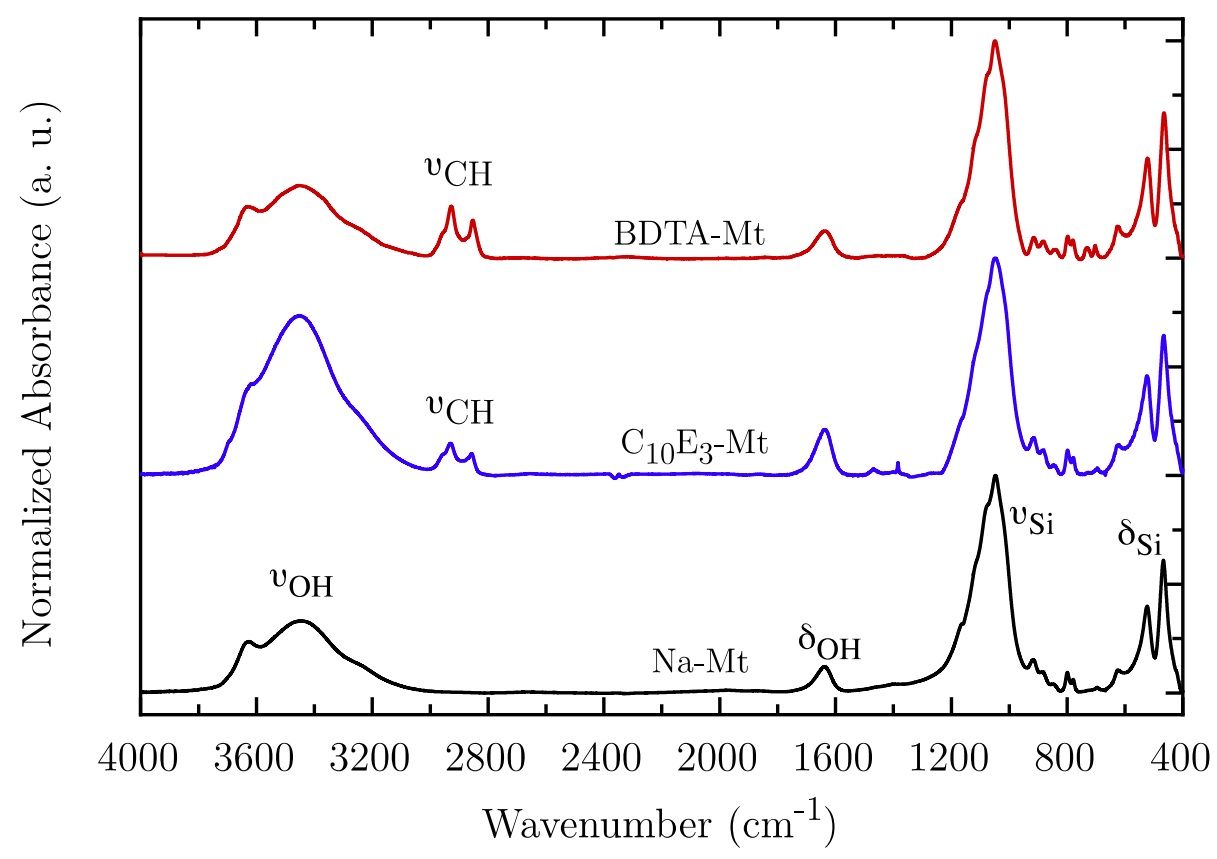

Figure 3: FTIR spectra of the Na-Mt, $\mathrm{C}_{10} \mathrm{E}_{3}-\mathrm{Mt}$ and BDTA-Mt organoclays. The coating of surfactants is highlighted by the presence of additional absorbance bands relative to the $\mathrm{CH}_{2}$ stretching vibrations of the hydrocarbon chains of $\mathrm{C}_{10} \mathrm{E}_{3}$ and BDTA.

\subsection{Adsorption of an organic cation herbicide: the paraquat}

The affinity between paraquat a quaternary ammonium herbicide and the untreated Mt and the prepared organoclays was shown through the lineshape of the adsorption isotherms, which could be fit by using Langmuir equation model (Figure 4). The thermodynamic data and different Langmuir, Freundlich and D-R parameters point out the better affinity of paraquat for untreated Mt than organoclays which differs considerably from a previous study where cationic organoclays seemed to improve slightly the adsorption of the organic cation (Table 1). Here, both Langmuir and Freundlich constants for the determination of the adsorption of paraquat onto Mt are in good agreement with previous works as well as the maximum adsorbed amount at $5.2 \times 10^{-4} \mathrm{~mol}_{\mathrm{g}} \mathrm{g}^{-1}$, which matches the value of the CEC of Mt underlining electrostatic interaction as the main vector for the adsorption of paraquat [28-32]. This last point is confirmed through D-R fitting procedure with the magnitude of $E$ that reaches a value $>8 \mathrm{~kJ} \cdot \mathrm{mol}^{-1}$, stressing out an adsorption through ion exchange onto $\mathrm{Mt}$ as well as $\mathrm{C}_{10} \mathrm{E}_{3}-\mathrm{Mt}$. 


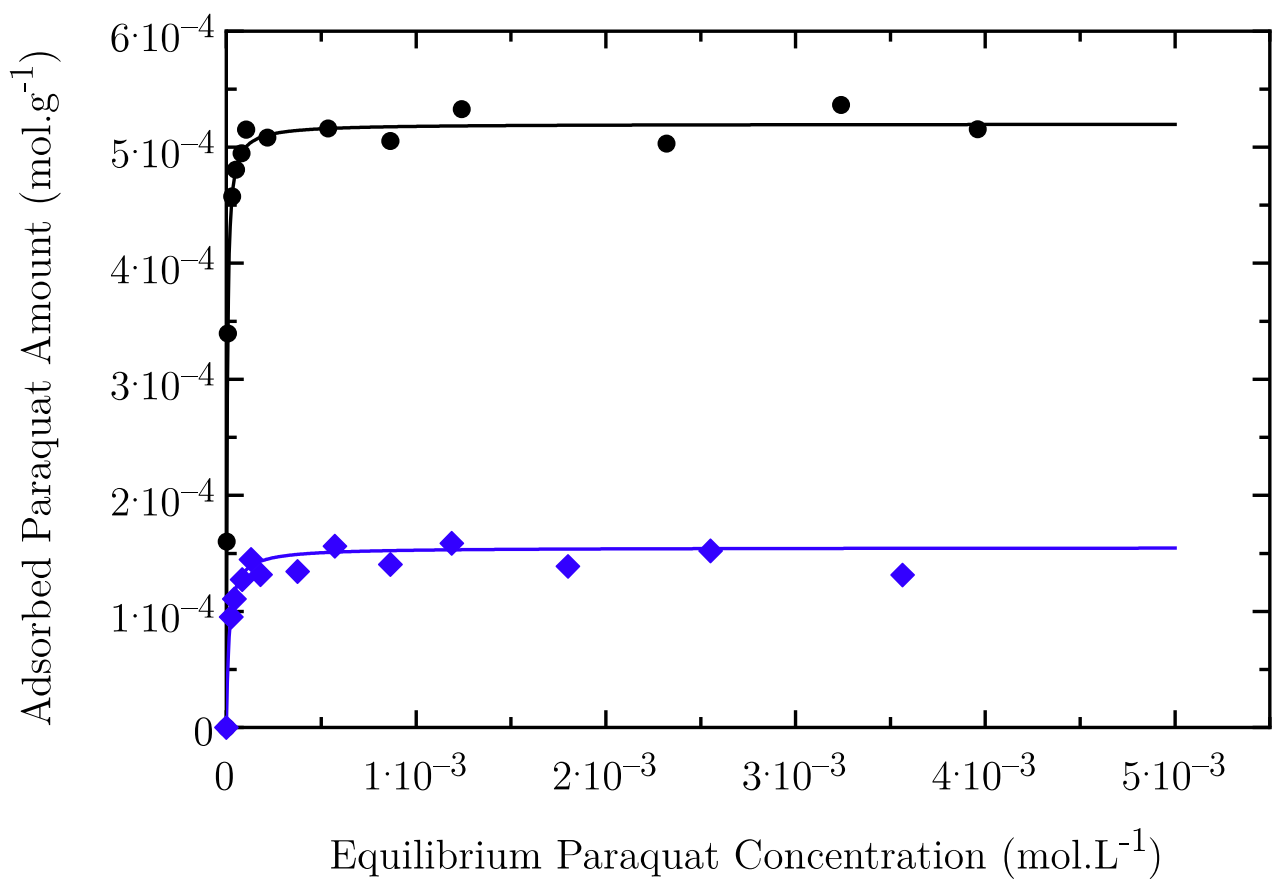

Figure 4: Adsorption isotherms of paraquat herbicide onto both $\mathrm{Na}-\mathrm{Mt}$ (black circles), and $\mathrm{C}_{10} \mathrm{E}_{3}-\mathrm{Mt}_{\text {nonionic organoclay }}$ (blue diamonds). The solid lines represent Langmuir model fit.

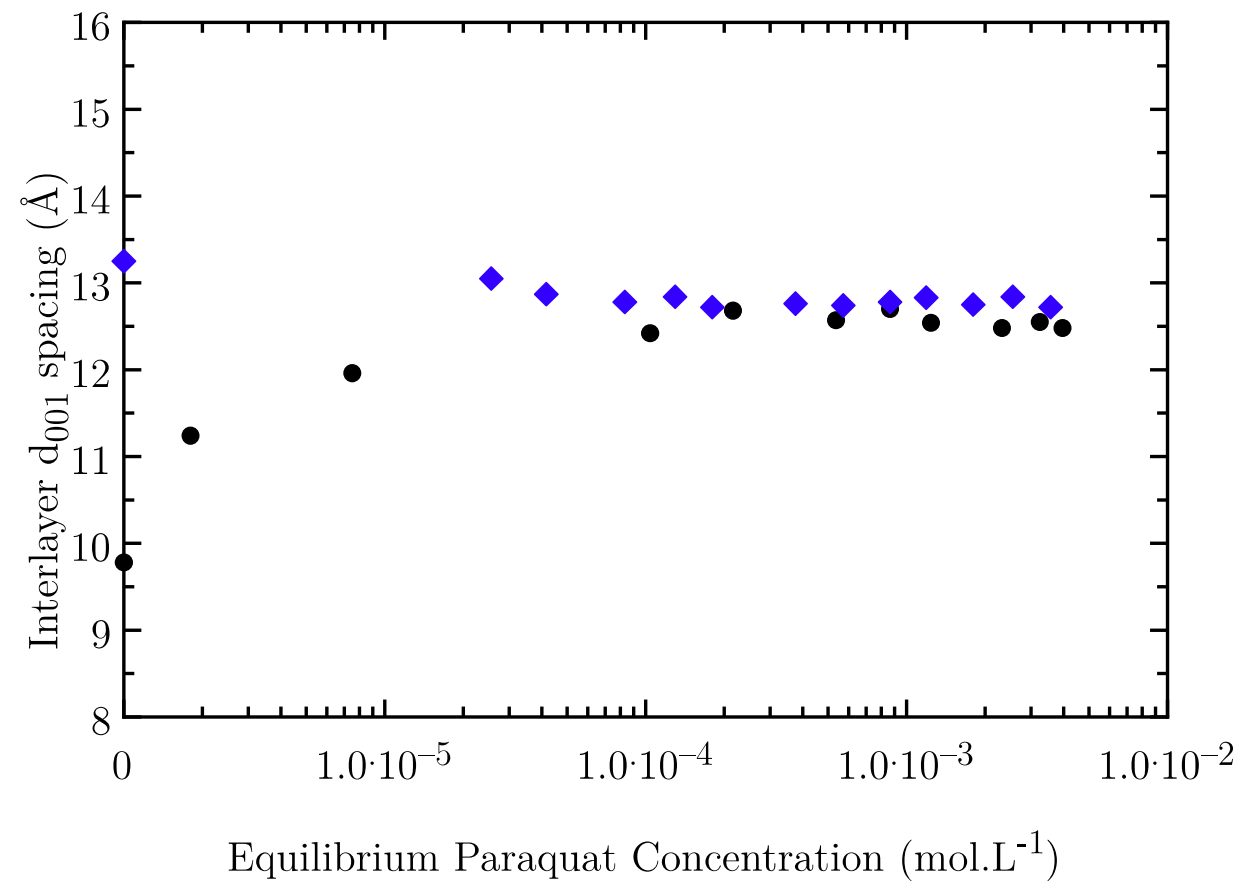

Figure 5: Evolution of the $d_{001}$ basal spacing determined by the $00 \mathrm{l}$ reflection of the silicates sheets obtained from X-ray diffraction patterns of Na-Mt (black circles), and $\mathrm{C}_{10} \mathrm{E}_{3}-\mathrm{Mt}$ nonionic organoclay (blue diamonds) after their impregnation in paraquat herbicide solutions at several concentrations for $48 \mathrm{~h}$. 
1

\begin{tabular}{|c|c|c|c|c|c|c|c|c|c|c|c|c|}
\hline \multirow[t]{2}{*}{ Pollutant } & \multirow[t]{2}{*}{ Adsorbent } & \multicolumn{4}{|l|}{ Langmuir } & \multicolumn{3}{|l|}{ Freundlich } & \multicolumn{4}{|c|}{ Dubinin-Radushkevich (D-R) } \\
\hline & & $\underset{\left(\mathrm{mol}_{\max } \mathrm{g}^{-1}\right)}{\mathrm{q}}$ & $\begin{array}{c}\mathrm{K}_{\mathrm{L}} \\
\left(\mathrm{L} \cdot \mathrm{mol}^{-1}\right)\end{array}$ & $\begin{array}{c}\Delta \mathrm{G}^{\circ} \\
\left(\mathrm{kJ} \cdot \mathrm{mol}^{-1}\right)\end{array}$ & $r^{2}$ & $\begin{array}{c}\mathrm{K}_{\mathrm{F}} \\
\left(\mathrm{L} \cdot \mathrm{g}^{-1}\right)\end{array}$ & $\mathrm{n}$ & $r^{2}$ & $\begin{array}{c}\mathrm{q}_{\mathrm{m}} \\
\left(\mathrm{mol} \cdot \mathrm{g}^{-1}\right)\end{array}$ & $\begin{array}{c}\beta \\
\left(\mathrm{mol}^{2} \cdot \mathrm{kJ}^{-2}\right)\end{array}$ & $\begin{array}{c}\mathrm{E} \\
\left(\mathrm{kJ} \cdot \mathrm{mol}^{-1}\right)\end{array}$ & $r^{2}$ \\
\hline & Mt & $5.2 \times 10^{-4}$ & $2.44 \times 10^{5}$ & 30.5 & 0.995 & $5.88 \times 10^{-4}$ & 51,28 & 0.903 & $5.89 \times 10^{-4}$ & $1.796 \times 10^{-9}$ & 16,68 & 0.901 \\
\hline Paraquat & $\begin{array}{l}\text { BDTA-Mt } \\
\mathrm{C}_{10} \mathrm{E}_{3}-\mathrm{Mt}\end{array}$ & $1.5 \times 10^{-4}$ & $6.8 \times 10^{4}$ & $2 \overline{7} .3$ & $0 . \overline{99}$ & $1.89 \overline{-} \times 10^{-4}$ & 24.04 & $0 . \overline{9} 19$ & $1.88 \times 10^{-4}$ & $3.397^{-} \times 10^{-9}$ & $12 \overline{-} .13$ & $0 . \overline{9} 10$ \\
\hline Benzene & $\begin{array}{l}\text { Mt } \\
\text { BDTA-Mt } \\
\mathrm{C}_{10} \mathrm{E}_{3}-\mathrm{Mt}\end{array}$ & $\begin{array}{l}1.64 \times 10^{-4} \\
1.09 \times 10^{-4}\end{array}$ & $\begin{array}{l}4.3 \times 10^{3} \\
2.7 \times 10^{3}\end{array}$ & $\begin{array}{l}20.8 \\
19.6\end{array}$ & $\begin{array}{c}0.954 \\
0.967\end{array}$ & $\begin{array}{l}8.34 \times 10^{-4} \\
7.62 \times 10^{-4}\end{array}$ & $\begin{array}{c}3,54 \\
2.875\end{array}$ & $\begin{array}{l}0 . \overline{9} 00 \\
0.943\end{array}$ & $\begin{array}{l}8.35 \times 10^{-4} \\
7.65 \times 10^{-4}\end{array}$ & $\begin{array}{c}-\overline{-} \\
2.306 \times 10^{-8} \\
2.838 \times 10^{-8}\end{array}$ & $\begin{array}{l}4.60 \\
4.19\end{array}$ & $\begin{array}{l}0 . \overline{9} 04 \\
0.944\end{array}$ \\
\hline $\begin{array}{l}\text { Dimethyl } \\
\text {-Phthalate }\end{array}$ & $\begin{array}{l}\text { Mt } \\
\text { BDTA-Mt } \\
\mathrm{C}_{10} \mathrm{E}_{3}-\mathrm{Mt}\end{array}$ & $\begin{array}{l}1.87 \times 10^{-3} \\
1.07 \times 10^{-3} \\
1.21 \times 10^{-3} \\
\end{array}$ & $\begin{array}{l}2.91 \times 10^{4} \\
1.73 \times 10^{4} \\
1.85 \times 10^{4} \\
\end{array}$ & $\begin{array}{l}25.7 \\
23.8 \\
24.3 \\
\end{array}$ & $\begin{array}{l}0.987 \\
0.995 \\
0.984 \\
\end{array}$ & $\begin{array}{l}3.10 \times 10^{-3} \\
2.07 \times 10^{-3} \\
2.25 \times 10^{-3} \\
\end{array}$ & $\begin{array}{l}11.58 \\
8.93 \\
9.77 \\
\end{array}$ & $\begin{array}{l}0.865 \\
0.903 \\
0.907 \\
\end{array}$ & $\begin{array}{l}3.11 \times 10^{-3} \\
2.03 \times 10^{-3} \\
2.21 \times 10^{-3} \\
\end{array}$ & $\begin{array}{l}7.433 \times 10^{-9} \\
9.136 \times 10^{-9} \\
8.346 \times 10^{-9} \\
\end{array}$ & $\begin{array}{l}8.20 \\
7.39 \\
7.74 \\
\end{array}$ & $\begin{array}{l}0.865 \\
0.903 \\
0.907 \\
\end{array}$ \\
\hline
\end{tabular}

Table 1. Adsorption isotherm constants determined with Langmuir, Freundlich, and Dubinin-Radushkevich model fit for the adsorption of organic contaminants onto Mt, BDTA-Mt, and $\mathrm{C}_{10} \mathrm{E}_{3}$-Mt organoclays.

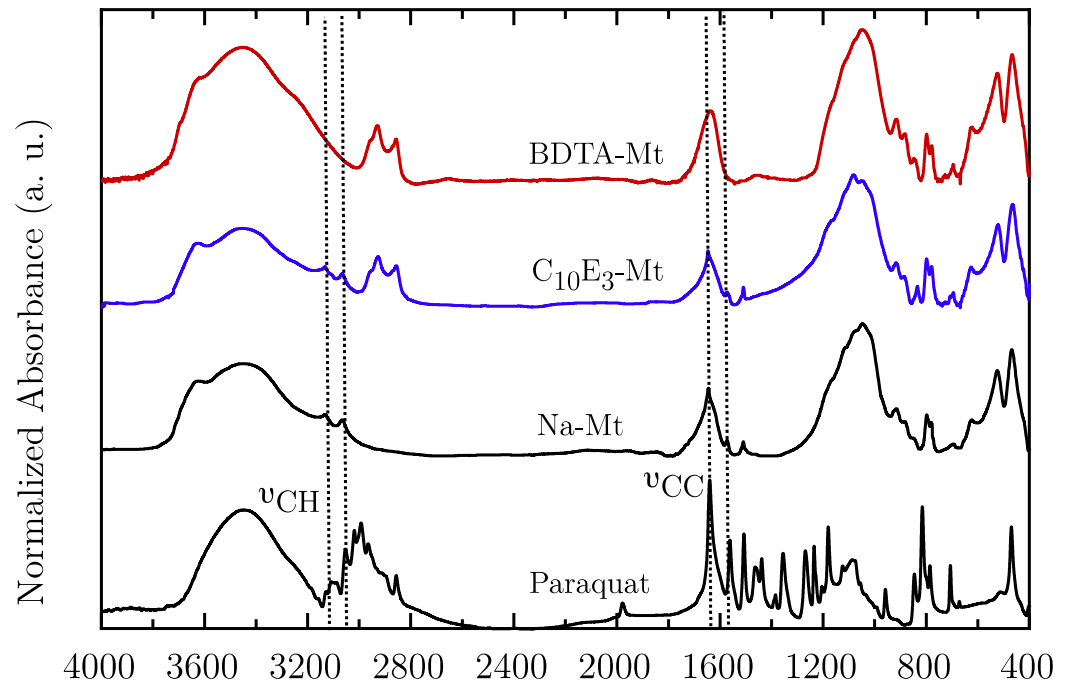

Wavenumber $\left(\mathrm{cm}^{-1}\right)$

Figure 6: FTIR spectra - from bottom to top - of the paraquat, and Na-Mt, $\mathrm{C}_{10} \mathrm{E}_{3}-\mathrm{Mt}$ as well as BDTA-Mt sorbents after being impregnated in paraquat at high concentration regime (concentration range once a plateau for the adsorbed amount is reached). Spectra were normalized with respect to the Si-O stretching band at $1100 \mathrm{~cm}^{-1}$. The adsorption of paraquat onto Na-Mt and $\mathrm{C}_{10} \mathrm{E}_{3}-\mathrm{Mt}$ is confirmed by the presence of additional absorption bands relative of the alkyl stretching modes at $2850-3000 \mathrm{~cm}^{-1}$, aromatic C-C stretching vibrations 1570 and $1620 \mathrm{~cm}^{-1}$ which are highlighted by dashed lines whereas BDTA-Mt spectrum does not show any evidence of these particular bands. 
Nevertheless, although paraquat shows a particular affinity for the nonionic organoclay, it never reaches the magnitude for the untreated Mt as both Langmuir and Freundlich constants expressed. Moreover, the estimation of the maximum of adsorbed paraquat represents 0.3 times the CEC of the layered materials, which indicates that only a part of the whole accessible $\mathrm{Na}^{+}$cations are exchanged. From isotherm data, we may think that the spatial arrangement of $\mathrm{C}_{10} \mathrm{E}_{3}$ in a lateral monolayer within the interlayer space should block the intercalation of paraquat due to steric effect leaving an exchange with the $20 \%$ of the $\mathrm{Na}^{+}$ cations located on the external surface of clay particle. However, XRD patterns revealed a shift of the $00 l$ reflection to large angular value, suggesting a contraction of the interlayer space at a value of $12.75 \AA$, equivalent to the $\mathrm{d}_{001}$ of the Mt after being impregnated into paraquat solutions (Figure 5). Such $\mathrm{d}_{001}$ spacing conveys a planar arrangement for the intercalation of paraquat within the interlayer space of Mt as well as $\mathrm{C}_{10} \mathrm{E}_{3}$-Mt and suggests that $\mathrm{Na}^{+}$cations involved in the exchange with paraquat are mainly located within the interlayer space for the nonionic organoclay. A control of the supernatant after the impregnation into paraquat solution revealed that $\mathrm{C}_{10} \mathrm{E}_{3}$ was not expelled from the layered structure of the organoclay and the density of $\mathrm{C}_{10} \mathrm{E}_{3}$ remains strictly identical as FTIR spectra exhibited. Indeed, the integrated intensity of $\mathrm{CH}_{2}$ stretching bands at $2850-2920 \mathrm{~cm}^{-1}$ related to the alky tails of $\mathrm{C}_{10} \mathrm{E}_{3}$ evolved gradually as the density of surfactant increases and was proposed as a probe for adsorption isotherm study $[13,17,18]$. These two bands did not show any significant difference before and after the impregnation in the pollutant solution whereas new absorption bands attributed to paraquat could be identified (Figure 6). Once intercalated, paraquat as a divalent organic cation, in contrast to $\mathrm{Na}^{+}$may considerably reduce the electrostatic repulsion between the phylosilicate layers and as a result stabilize the composite materials with a shrinking of its interlayer space. Despite a small loadings of $\mathrm{C}_{10} \mathrm{E}_{3}$, only a few part of the accessible $\mathrm{Na}^{+}$cations (30\%) are involved in the exchange with paraquat. This 
can be explained by the possible lining of the linear arrangement of $\mathrm{C}_{10} \mathrm{E}_{3}$ around the inorganic cations preventing any cation exchange.

In contrast to raw clay mineral, cationic organoclay usually showed an improvement for the adsorption of numerous organic compounds due to their hydrophobic behavior and a wide opening of the interlayer space $[10,14]$. However, in the case of paraquat, these last points play minor roles since the adsorption is mainly driving through electrostatic interaction [2832]. Although keeping some $\mathrm{Na}^{+}$cations, however at small ratio, chemical analysis of the supernatant as well as XRD and FTIR characterizations showed that BDTA-Mt was not suitable for the adsorption of paraquat. The previous study of Seki and Yurdakoç pointed out the capacity of cationic organoclays prepared with nonyl- and dodecylammonium surfactants for the sequestration of paraquat, which was somehow improved compared to the untreated clay minerals [32]. The authors stressed out the ion-exchange as the main adsorption mechanism between paraquat and the cationic surfactant previously adsorbed onto clay mineral. Although using a different chemical nature for the cationic surfactant as modifier and maybe a different protocol for the impregnation of the organoclays into the contaminant solution, the results presented here support that BDTA-Mt as a cationic organoclay is ineffective for the adsorption of inorganic and organic cationic compounds or at least is not the most appropriate sorbent. Indeed, numerous studies revealed such failure for cationic organoclay in which surfactant binds irreversibly to the interlayer of the base clay mineral, excluding any further ion-exchange with both inorganic and organic compounds. Nevertheless, cationic organoclay could adsorb in a smaller proportion through ion complexation or Van der Waals interaction trace elements and organic cationic compounds respectively $[33,34]$. Despite the generation of a hydrophobic environment with BDTA and the preparation of the cationic organoclay at $70 \%$ of the CEC, the whole data confirms the no paraquat adsorption. Moreover, the phenyl rings of BDTA in contrast to the linear form of 
$\mathrm{C}_{10} \mathrm{E}_{3}$ may block the herbicide cation from the phenyl rings, thereby reducing considerably the sorption, which only solicit the external surface of particles. Thus, it appears that paraquat mainly interact through electrostatic interaction and as a result cannot be properly sequestrated by using a BDTA-Mt.

\subsection{Adsorption of a nonpolar hydrophobic contaminant: the benzene}

The adsorption of benzene has been intensively studied with the use of numerous porous materials such as actived carbon, clay minerals and organoclays [35-39]. If cationic organoclays show a certain capacity to retain such nonpolar compound, clay minerals cannot adsorb it [35-39]. With the use of montmorillonite deploying a BET specific surface of 35 $\mathrm{m}^{2} \cdot \mathrm{g}^{-1}$, we obtained similar results to previous studies with the no benzene sorption by the untreated clay mineral. Both chemical analysis of the supernatant, in the limit of the resolution of the analytical methods, and solid characterizations (FTIR and XRD) of Mt after impregnation in solution at high benzene concentration, did not show any traces of its adsorption (Figures 7-9). As expected, the absence or low content of organic carbon in the starting clay mineral, of which behavior is mainly hydrophilic, cannot retain nonpolar hydrophobic compounds and is consistent with previous works $[35,38]$.

On the other hand, the chemical modification with $\mathrm{C}_{10} \mathrm{E}_{3}$ and BDTA surfactants, even at low loadings, provides an adequate media for the adsorption of nonpolar hydrophobic compound. If the density of surfactant increases a hydrophobic character, the improvement of the adsorption properties of organoclays for non-polar hydrophobic pollutants does not evolve linearly and depends on both the chemical nature of the surfactant and its arrangement. Indeed, for organoclays with cationic phenyl rings surfactants (BDTA or BTEA for instance) at small loadings (5-7\% of organic content) showed a maximum uptake for nonpolar compounds while 
organoclays prepared by linear surfactants with long alkyl tails (HDTMA) demonstrated the opposite trend [38].

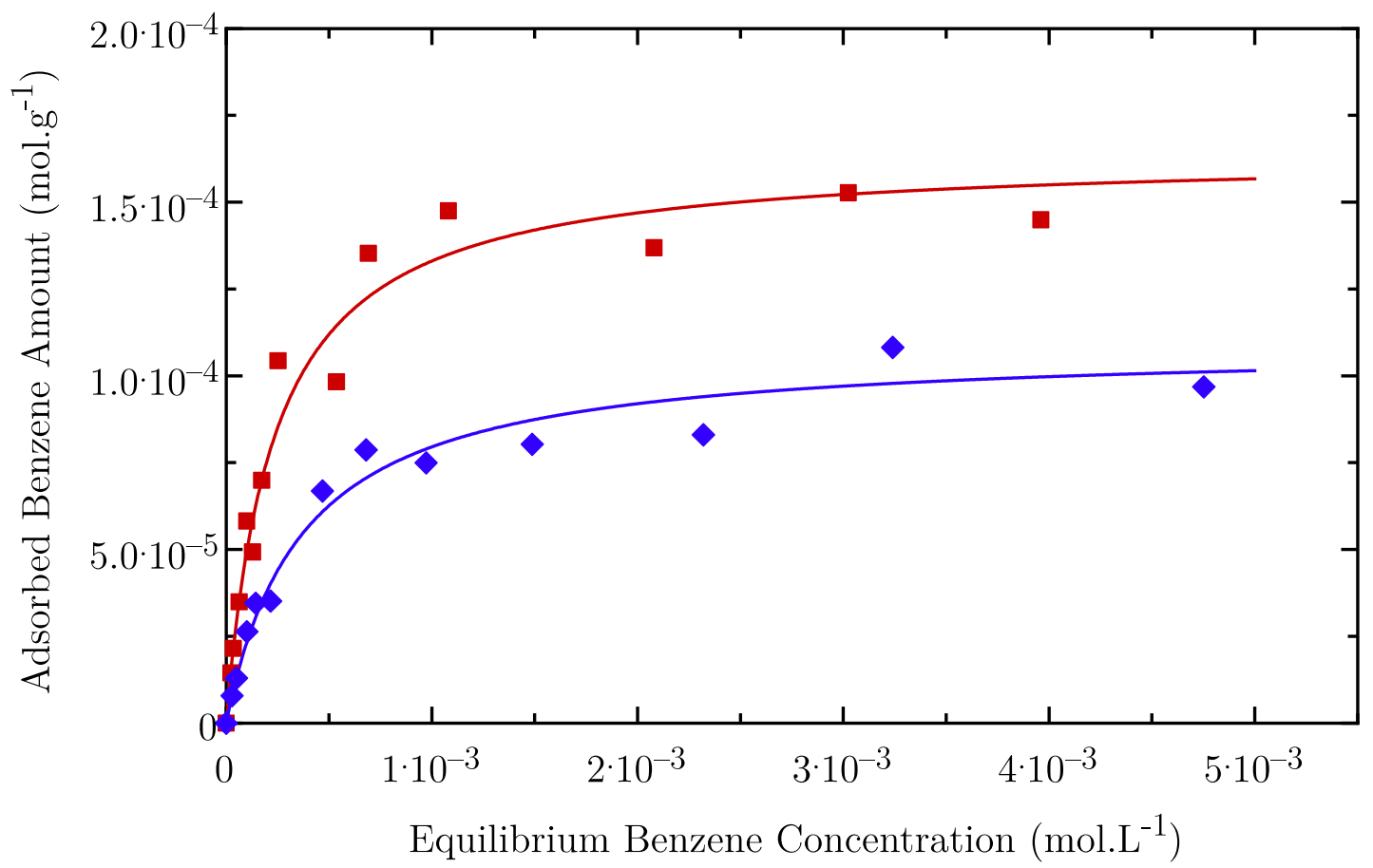

Figure 7: Adsorption isotherms of nonpolar hydrophobic benzene onto $\mathrm{C}_{10} \mathrm{E}_{3}-\mathrm{Mt}$ nonionic organoclay (blue diamonds) and BDTA-Mt cationic organoclay (red squares). The solid lines represent Langmuir model fit.

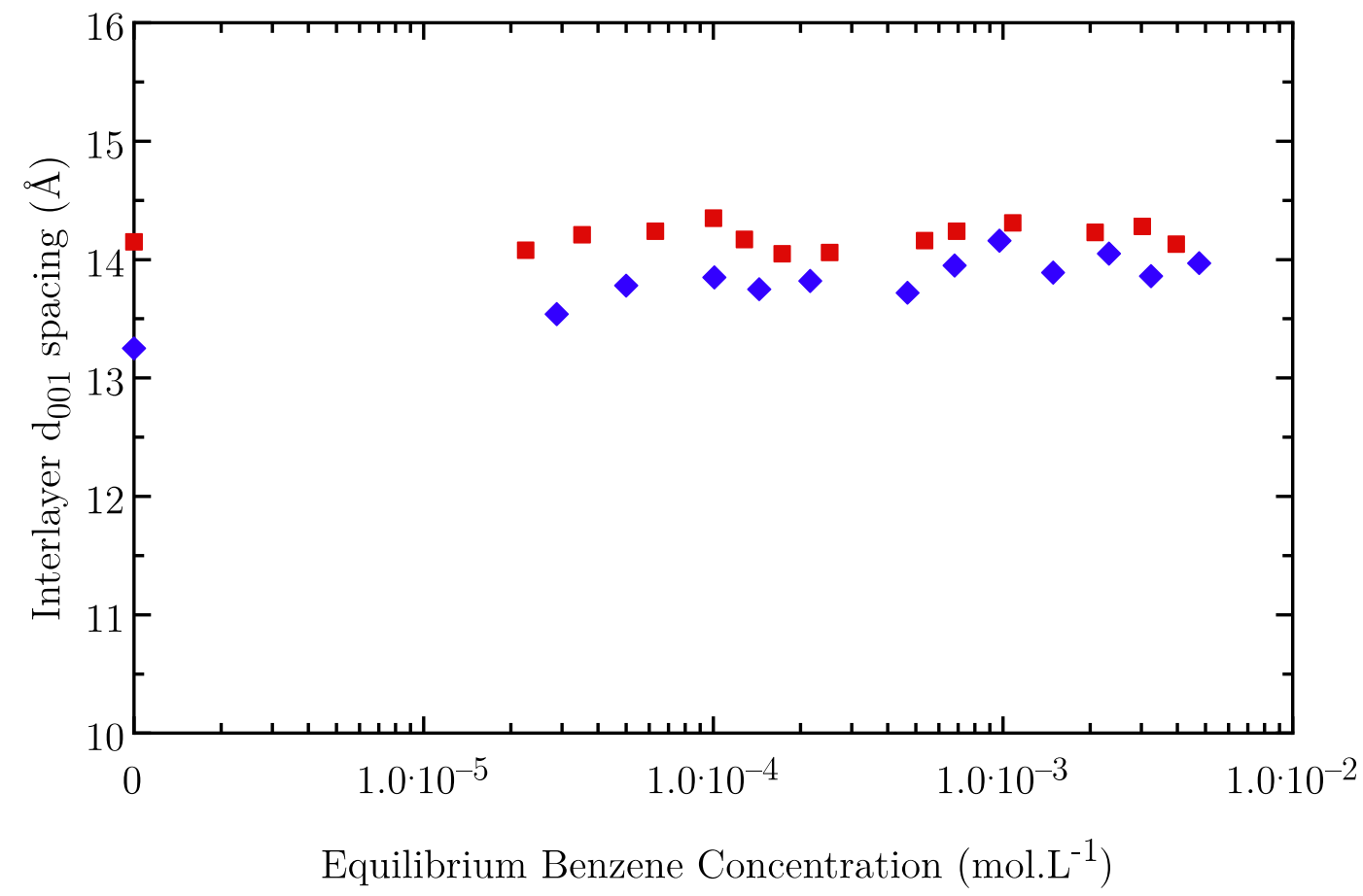

Figure 8: Evolution of the $d_{001}$ basal spacing determined by the $00 l$ reflection of the silicates sheets obtained from X-ray diffraction patterns of BDTA-Mt cationic organoclay (red squares) and $\mathrm{C}_{10} \mathrm{E}_{3}$-Mt nonionic organoclay (blue diamonds) after being impregnated in benzene solutions as a function of the equilibrium nonpolar hydrophobic compound concentration. 
The adsorption isotherms of benzene on $\mathrm{C}_{10} \mathrm{E}_{3}-\mathrm{Mt}$ and BDTA-Mt show similar behavior where the adsorbed benzene amount nonlinearly grows, and the lineshapes are perfectly fit with a Langmuir model (Figure 7). The parameters derived from the fitting procedure clearly show the preferential affinity of benzene for BDTA-Mt with $\mathrm{K}_{\mathrm{L}}>$ than $\mathrm{C}_{10} \mathrm{E}_{3}$-Mt (Table 1). Moreover, the maximum benzene adsorbed amount follows the same trend by reaching at the plateau of adsorption 1.09 and $1.64 \times 10^{-4}$ mol.g ${ }^{-1}$ for $\mathrm{C}_{10} \mathrm{E}_{3}-\mathrm{Mt}$ and BDTA-Mt. Both Freundlich and D-R models overestimates the maximum of adsorption which may indicates a monolayer covering of benzene onto organoclays as well as none variability for the adsorption potentials. Despite the intercalation of long alkyl surfactants leading to new possible adsorption sites, BET specific surface area of organoclays usually decreases with organic content due to surfactant block in Mt micropores [38]. Nevertheless, for 5.2 and $6.1 \%$ surfactant loadings, $\mathrm{C}_{10} \mathrm{E}_{3}$-Mt and BDTA-Mt showed a BET surface area of 28 and $25 \mathrm{~m}^{2} \cdot \mathrm{g}^{-1}$ respectively. Benzene displays a spherical geometry with a $2.8 \AA$ radius, yielding to an apparent packing area per molecule of $26 \AA^{2}$. If we assume the entire surface of both organoclays is totally accessible, the calculated amount of benzene covering in monolayer reaches 1.82 and $1.73 \times 10^{-4} \mathrm{~mol} . \mathrm{g}^{-1}$ for $\mathrm{C}_{10} \mathrm{E}_{3}-\mathrm{Mt}$ and BDTA-Mt respectively. Such adsorbed amount of benzene suggests its complete or partial lining onto the whole organoclay surface including that of the interlayer space. While the $\mathrm{d}_{001}$ spacing of $\mathrm{C}_{10} \mathrm{E}_{3}$-Mt gradually increases following the equilibrium benzene concentration and reaches for high concentration a value of $14 \AA$, consistent with the size of the intercalated organic compounds, the BDTA-Mt interlayer spacing remains at its original value of $14.2 \AA$ (Figure 8). Benzene is somehow quite a small molecule, which can be easily blended among the alkyl tails without introducing any significant change of the interlayer space of the cationic organoclay. FTIR spectra of the resulting organoclays after their impregnation into high concentrated benzene solution 
confirmed its proper sequestration with the identification of absorption bands characteristics of this nonpolar hydrophobic compound (Figure 9).

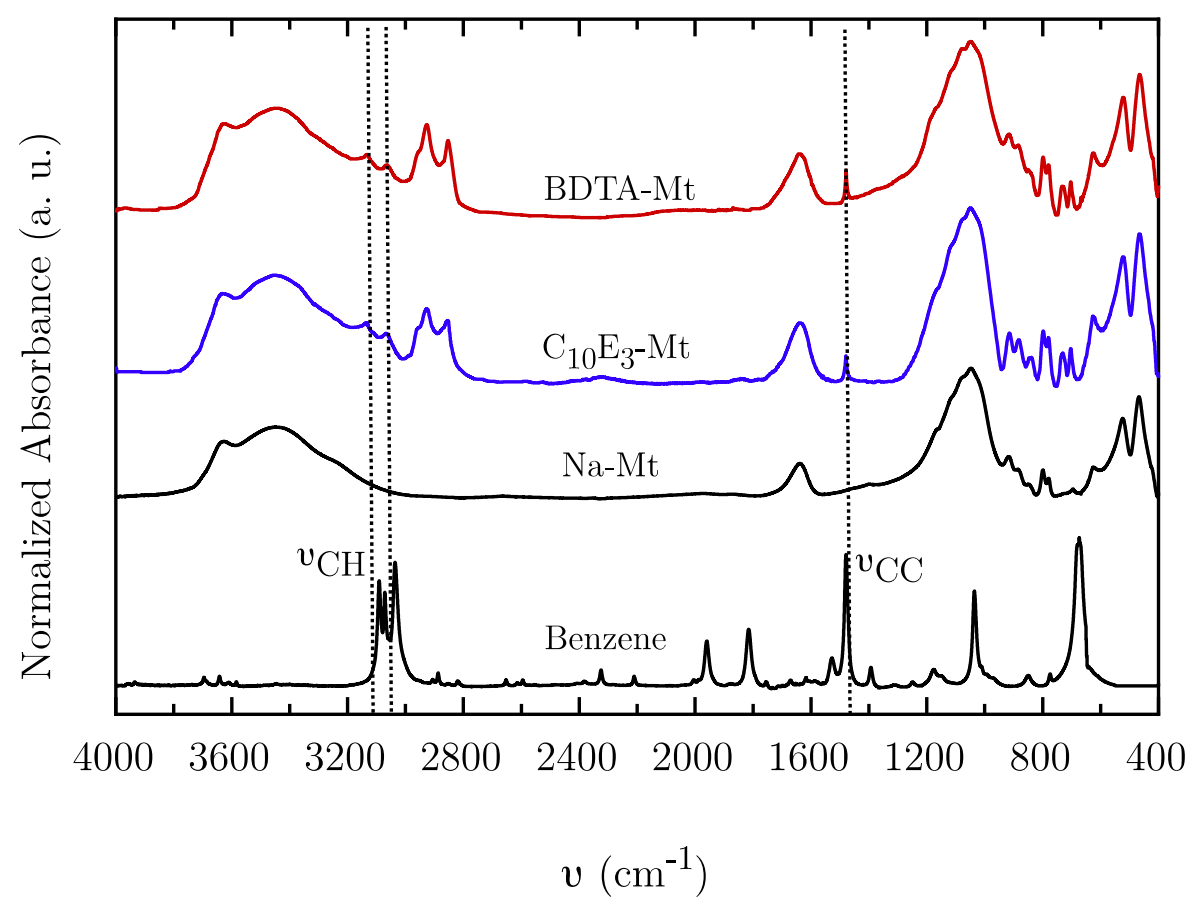

Figure 9: FTIR spectra - from bottom to top - of the benzene, and Na-Mt, $\mathrm{C}_{10} \mathrm{E}_{3}-\mathrm{Mt}$ as well as BDTA-Mt sorbents after being impregnated in this nonpolar hydrophobic compound at high concentration regime (concentration range once a plateau for the adsorbed amount is reached). Spectra were normalized with respect to the Si-O stretching band at $1100 \mathrm{~cm}^{-1}$. While Na-Mt after being impregnated in benzene did not show any additional bands attesting the no sorption of this compound, the confirmation of its proper adsorption onto both organoclays is highlighted by representative absorption bands attributed to $\mathrm{CH}$ stretching vibrations at 2850$3000 \mathrm{~cm}^{-1}$ and $\mathrm{C}=\mathrm{C}$ stretching modes at $1450-1500 \mathrm{~cm}^{-1}$ of benzene (dashed lines).

As a non-polar hydrophobic compound, even though D-R fit process overestimates the maximum of adsorbed amount; this model gives an idea of the energy involved for the benzene adsorption onto organoclays, which are below $8 \mathrm{~kJ} \cdot \mathrm{mol}^{-1}$ confirming a physisorption mechanism. The alkyl carbon chains of both surfactants contribute to weak short range Van der Waals interaction with benzene as well as phenyl ring-ring interaction for BDTA-Mt. This last contribution, although displaying a shorter accessible surface area and pore space favors an adsorption of benzene in contrast to $\mathrm{C}_{10} \mathrm{E}_{3}-\mathrm{Mt}$ with $60 \%$ of its surface covered by benzene shows its ability to adsorb such kind of chemical product. 


\subsection{Adsorption of the dimethyl-phthalate}

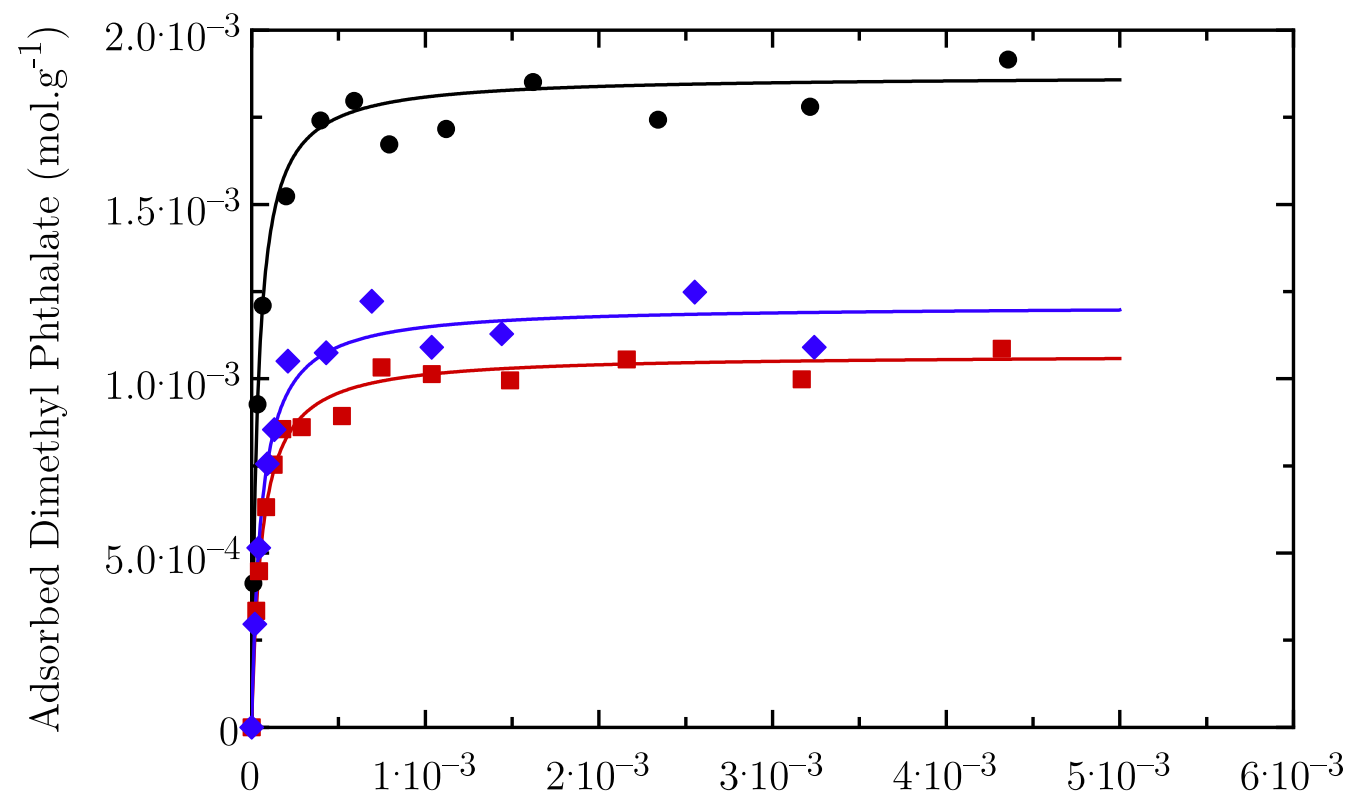

Equilibrium Dimethyl Phthalate Concentration $\left(\right.$ mol.L $\left.{ }^{-1}\right)$

Figure 10: Adsorption isotherms of dimethyl phthalate Na-Mt (black circles), BDTA-Mt cationic organoclay (red squares) and $\mathrm{C}_{10} \mathrm{E}_{3}$-Mt nonionic organoclay (blue diamonds). The solid lines represent Langmuir model fit.

Among alkyl-phthalate compounds, dimethyl-phthalate (DP) with the smallest partition coefficient $\mathrm{K}_{\mathrm{o} / \mathrm{w}}$, represents the most hydrophilic compound in the phthalate series which has been identified in diverse environmental media, and more particularly in drinking water [40,41]. The affinity of DP with the two organoclays and Mt was shown with its nonlinear growth of the adsorbed amount as a function of its equilibrium concentration (Figure 10). If the adsorption isotherms are well fit by Langmuir equation model with parameters like the maximum adsorbed amount, which matches the experimental data, the parameters determined through Freundlich or D-R models overestimate the maximum adsorbed amount (Table 1). Both Freundlich and D-R parameters even though departing from experimental data with a $\approx 50 \%$ error deviation follow the same trend as Langmuir constants stressing out the affinity of DP which decreases in the following order: $\mathrm{Mt}>\mathrm{C}_{10} \mathrm{E}_{3}-\mathrm{Mt}>\mathrm{BDTA}-\mathrm{Mt}$ with $\mathrm{K}_{\mathrm{L}}$ of DP for Mt $68 \%$ and $57 \%$ greater than the cationic and nonionic organoclays respectively. This sorbents affinity rank for DP goes against what could be thought where the hydrophobic character of organoclays, identified as a key parameter in phthalates adsorption [40-44]. appears here to 
play finally a minor role in the sequestration of DP. Indeed, if hydrophobic interaction was the main driving force for the adsorption of DP onto the studied sorbents, the entire Langmuir, Freundlich and DR constants would have been greater for both organoclays than the untreated Mt which is obviously not the case here.

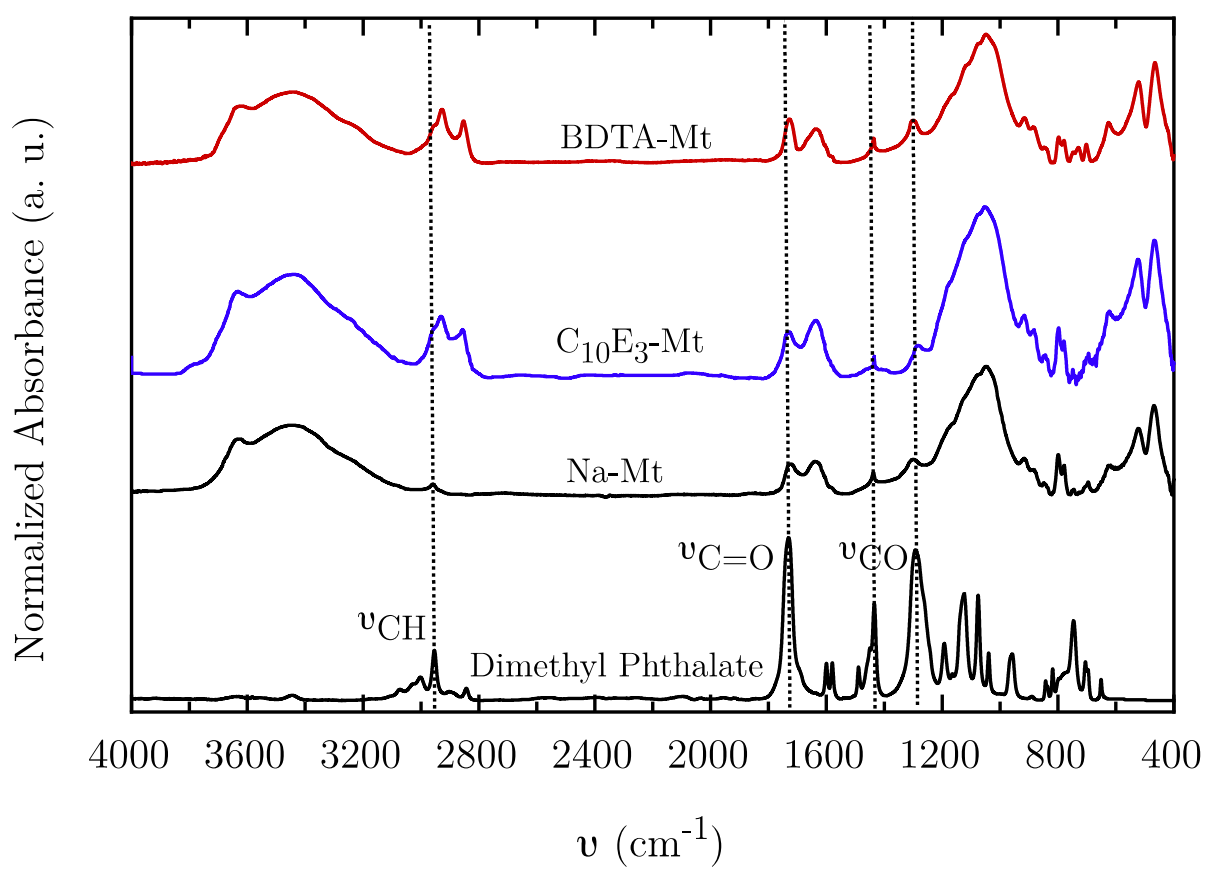

Figure 11: FTIR spectra - from bottom to top - of the dimethyl phthalate, and Na-Mt, $\mathrm{C}_{10} \mathrm{E}_{3}-\mathrm{Mt}$ as well as BDTA-Mt sorbents after being impregnated in dimethyl phthalate at high concentration regime (concentration range once a plateau for the adsorbed amount is reached). Spectra were normalized with respect to the $\mathrm{Si}-\mathrm{O}$ stretching band at $1100 \mathrm{~cm}^{-1}$. The adsorption of dimethyl phthalate onto whole sorbents is confirmed by the presence of additional absorption bands relative of the $\mathrm{CH}_{3}$ stretching vibration at $2850-3000 \mathrm{~cm}^{-1}, \mathrm{C}-\mathrm{O}$ and $\mathrm{C}=\mathrm{O}$ stretching bands of ester groups at 1300 and $1722 \mathrm{~cm}^{-1}$ which are highlighted by dashed lines.

Although D-R fit suffers from a lack of agreement with experimental data, the mean free energy $E$ estimated of the adsorption of DP onto sorbents follows the same affinity trend as established previously but the amplitude of these energies is somehow overestimated. Indeed, the energy involved of DP for Mt overcomes the threshold value of $8 \mathrm{~kJ}^{\mathrm{mol}}{ }^{-1}$ suggesting a chemisorption mechanism as an ion exchange. Even though it is impossible to completely exclude any hydrolyzation of DP to phthalic acid that can acquire a positive charge even in neutral $\mathrm{pH}$ conditions leading to an intercalation of these organic cations and in a second step DP molecule, this assumption is somehow quite unreasonable. Indeed, if such mechanisms 
prevail, it could not support the large adsorption of DP onto $\mathrm{C}_{10} \mathrm{E}_{3}-\mathrm{Mt}$ nor BDTA-Mt. Moreover, FTIR spectra of the sorbents after being impregnated in high concentrated DP solution did not put in evidence absorption bands related to carboxylic groups (Figure 11). Thus, we assumed that the energies of DP for sorbents determined through D-R model are somehow overestimated and are below $8 \mathrm{~kJ} \mathrm{~mol}^{-1}$ underlining as it was reported a physisorption mechanism for the adsorption of nonionic organic compounds [27,40,41]. In contrast to nonpolar hydrophobic pollutant like benzene and even larger phthalate compounds where the adsorption results to hydrophobic interaction and $\pi-\pi$ electron donor acceptor mechanism with hydrophobic substrate [41], DP with the highest hydrophilic character of the phthalates series and hydrogen bonding donor and acceptor functions of 0.8 owns the ability to form some H-bonds and as a result could be adsorbed through ion-dipole and $\mathrm{H}$-bonds interaction with its $-\mathrm{COOCH}_{3}$ group, which is consistent to the hydrophilic behavior of the sorbents. The greater hydrophilic behavior of the sorbents is, the larger of the adsorbed amount is. Since Mt shows a low silanol (Si-OH) density on its surface [45], the hydrophilic behavior of untreated Mt mainly results to the presence of exchangeable cations within the interlayer space. Such character is particularly enhanced with alkyl metal exchangeable cations as Na-Mt shows thus favoring the adsorption of nonionic organic compounds around them associated by ion-dipole interaction [23]. This sorption mechanism also contributes to the sorption of DP onto organaclays with the possible association of BDTA-DP through iondipole and $\mathrm{H}$-bonds between $\mathrm{C}_{10} \mathrm{E}_{3}$ and $\mathrm{DP}$ as well as ion-dipole interaction modulated around the accessible $\mathrm{Na}^{+}$cations in the nonionic $\mathrm{C}_{10} \mathrm{E}_{3}-\mathrm{Mt}$ organoclay. 


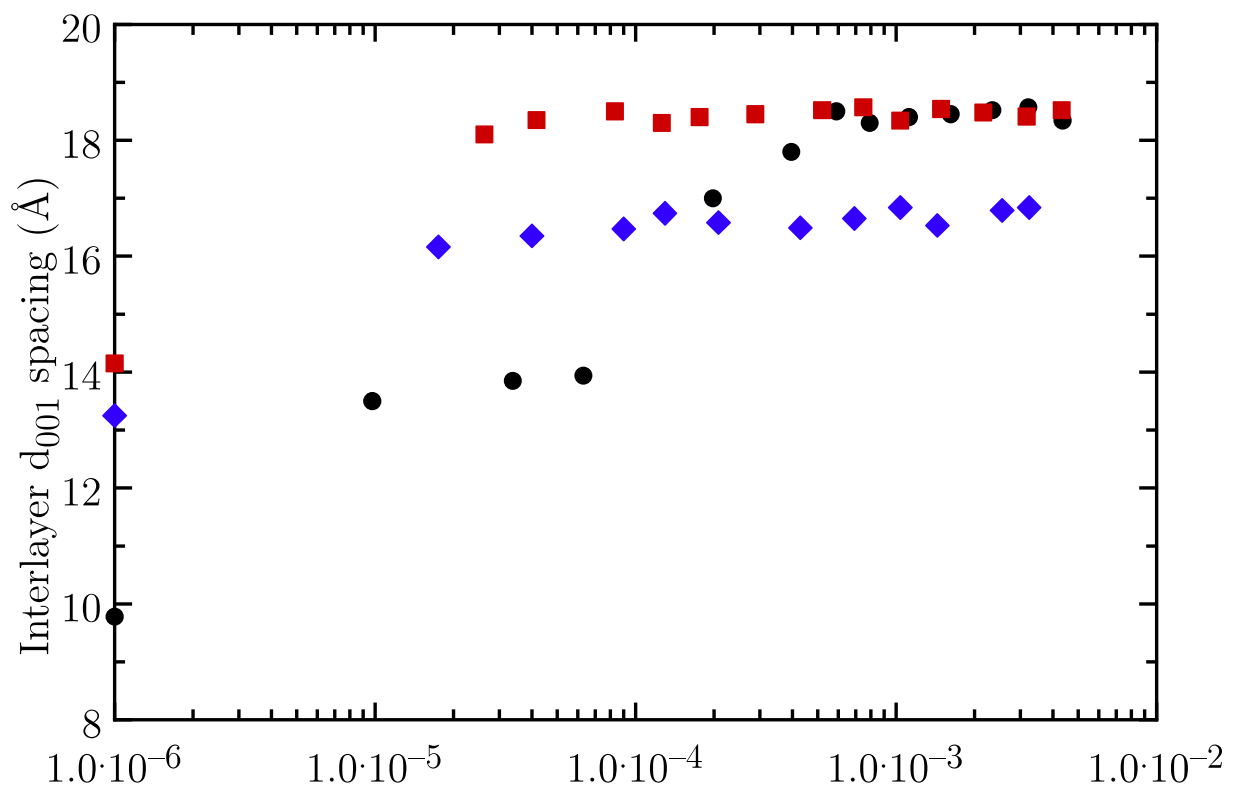

Equilibrium Dimethyl Phthalate Concentration (mol.L $\left.\mathrm{L}^{-1}\right)$

Figure 12: Evolution of the $d_{001}$ basal spacing determined by the $00 l$ reflection of the silicates sheets obtained from X-ray diffraction patterns of Na-Mt (black circles), BDTA-Mt cationic organoclay (red squares) and $\mathrm{C}_{10} \mathrm{E}_{3}$ Mt nonionic organoclay (blue diamonds) after being impregnated in dimethyl phthalate solutions as a function of the equilibrium contaminant concentration.

The wide layer expansion of Mt after the impregnation in DP solution with a $\mathrm{d}_{001}$ spacing of 18.2 A suggests a lateral bilayer arrangement of the contaminant within the interlayer space whereas for both organoclays, only a monolayer is confined with a $\mathrm{d}_{001}$ increase of $\approx 4 \AA$ (Figure 12). Such molecular arrangement is consistent with the adsorbed DP amount that matches the total accessible surface area of the entire sorbents which provide the major adsorption sites. For a proper understanding of the sorption of polar molecule, instead of considering BET specific surface area of sorbents which properly describes the adsorption of nonpolar molecule, it is rather preferable to take into account that one determined by ethylene glycol, a polar liquid, estimated at $660 \mathrm{~m}^{2} \cdot \mathrm{g}^{-1}$ [22]. The molecular volume of DP is approximately $600 \AA^{3}$ giving an area per molecule of $86 \AA^{2}$. The adsorption of DP was achieved in solution where the Mt suspension is well swollen and shows a stable hydration state in which the layers are widely expanded suggesting that the specific surface area is totally accessible. In that case, it leads to a calculated amount of DP in monolayer of $1.28 \mathrm{x}$ 
$10^{-3} \mathrm{~mol} \cdot \mathrm{g}^{-1}$ that exceeds the experimental data determined at the plateau of adsorption confirming a lateral bilayer organization within the interlayer space. It is possible to repeat this process for both organoclays even through the specific surface area may be reduced in view of their hydrophobic behavior and the block of intercalated surfactants within the interlayer space. The experimental and even the deduced adsorbed amount of DP through Langmuir fit, onto both organoclays are consistent with a lateral monolayer arrangement of the phthalate compound.

\section{Conclusions}

The chemical modification of clay minerals via the intercalation of cationic surfactants for the preparation of environmental organoclay obviously improves the efficiency of the adsorption of numerous chemicals $[10,14]$. Nevertheless, this observation is only correct for a restraint range of hydrophobic chemicals where cationic organoclays mainly excel, due to their hydrophobic character, but show some limits for other organic compounds [35]. Worse, cationic organoclays proved to be an inappropriate sorbent for cationic species where the irreversibility of the first adsorption of quaternary ammonium surfactants prevents any further ion exchange and as a result are permeable to such pollutant class $[33,34]$. If we neglect the nonpolar hydrophobic contaminant, untreated clay minerals appear to be the most efficient material for the adsorption of paraquat and DP chemicals where their large specific surface area and exchangeable cations provides a large adsorption sites. However, the identified recalcitrant contaminant in drinking water and other environmental samples are usually highly lipophilic large molecules where raw clay minerals show their adsorption limits. 


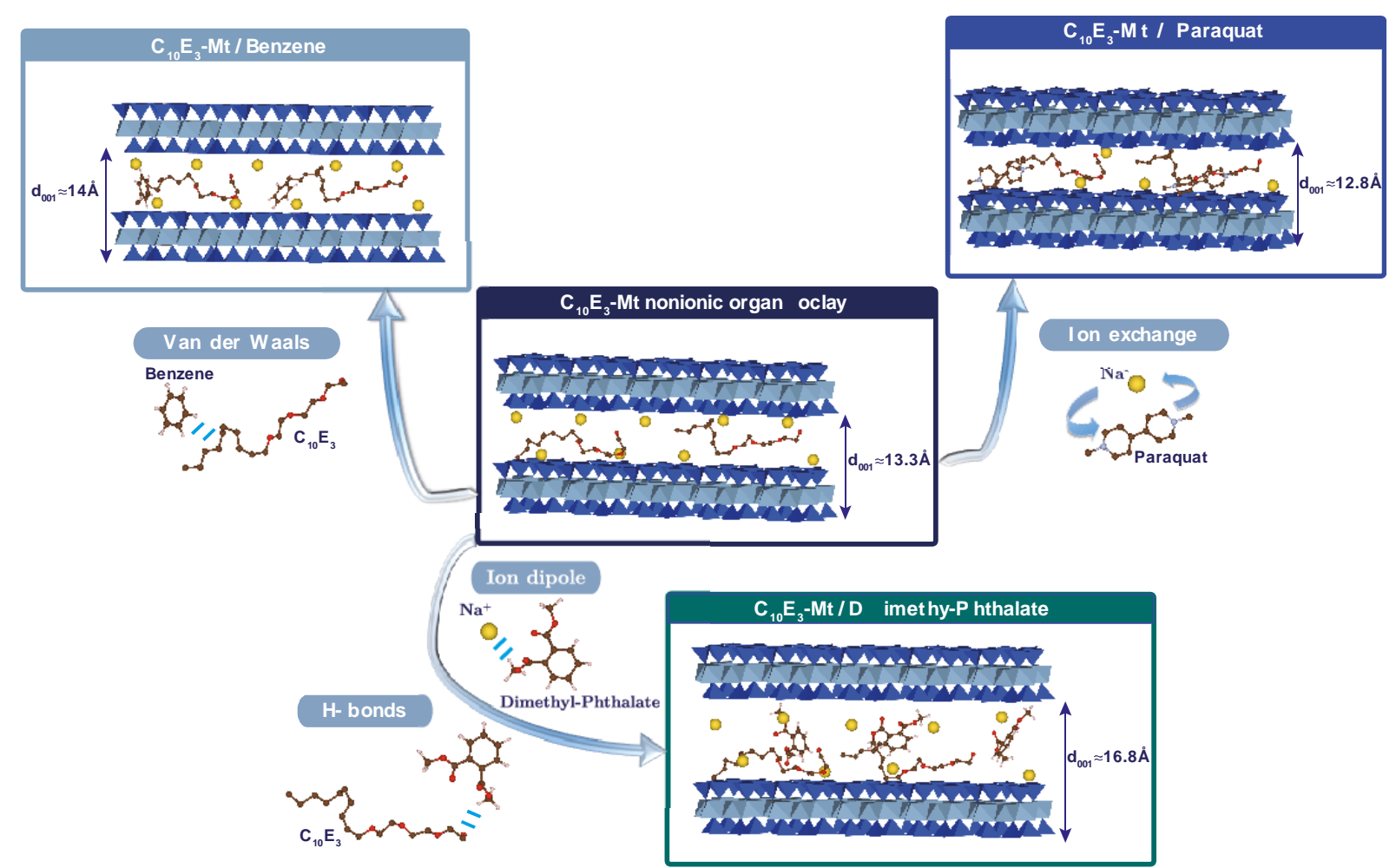

Figure 13: Possible adsorption mechanisms in a $\mathrm{C}_{10} \mathrm{E}_{3}$-Mt nonionic organoclay showing a lateral surfactant arrangement involved for the sequestration of paraquat, an organic herbicide cation(ion exchange); benzene, a nonpolar hydrophobic organic compound (hydrophobic interaction), and dimethyl-phthalate compound (ion dipole and $\mathrm{H}$-bonds interaction).

$\mathrm{C}_{10} \mathrm{E}_{3}-\mathrm{Mt}$ nonionic organoclay, although not being the best efficient sorbent in this study provide an interesting behavior since it could adsorb the entire studied contaminants. The large amplitude of this material for the adsorption of various chemical class results to its particular $\mathrm{C}_{10} \mathrm{E}_{3}$ coating onto Mt driving to a dual hydrophilic/hydrophobic behavior. While the introduction of amphiphilic molecules generates a hydrophobic media suitable for the adsorption of nonpolar hydrophobic compound through hydrophobic interaction, the accessibility of $\mathrm{Na}^{+}$cations allows the sequestration of cationic compounds by cation exchange and favors as well the adsorption of polar molecule through ion-dipole and H-bonds interaction (Figure 13). Therefore, such nonionic organoclay, by involving several possible adsorption mechanisms for the adsorption of various class contaminants, appears to be a convenient tool for environmental applications as a 'Swiss Army Knife' provides in daily life. However, since the adsorption efficiency mainly depends on the organic content in 
organoclay, the effect of nonionic surfactant density as well as the ratio between the hydrophilic to hydrophobic portion of the amphiphilic molecules adsorbed on clay mineral need to be examined along with other environmental factors like $\mathrm{pH}$ for instance.

\section{Acknowledgements}

We are grateful to the Canon Foundation in Europe for their support in this research, which allowed the first author to be hosted in laboratory of the Professor Ogawa at the University of Waseda last year 2013 for 6 months where some experiments were performed.

\section{Associated Content}

Additional figures on Freundlich and Dubinin-Radushkevish (D-R) fits of the adsorption isotherms of the micro-pollutants on the three sorbents are included. 


\section{References}

[1] G.A. Ayoko, K. Singh, S. Balerea, S. Kokot, Journal of Hydrology 336 (2007) 115-124.'

[2] P. Boffetta, Mutation Research/Genetic Toxicology and Environmental Mutagenesis 608 (2006) 157162.

[3] J. Dich, S. Zahm, A. Hanberg, H.-O. Adami, Cancer Causes \& Control 8 (1997) 420-443.

[4] B. Chen, L. Zhu, J. Zhu, B. Xing, Environmental Science \& Technology 39 (2005) 6093-6100.

[5] C.T. Johnston, B. Khan, E.F. Barth, S. Chattopadhyay, S.A. Boyd, Environmental Science \& Technology 46 (2012) 9584-9591.

[6] Q. Zhao, S.E. Burns, Environmental Science \& Technology 47 (2013) 2769-2776.

[7] L. Zhu, B. Chen, S. Tao, C.T. Chiou, Environmental Science \& Technology 37 (2003) 4001-4006.

[8] L. Zhu, X. Ren, S. Yu, Environmental Science \& Technology 32 (1998) 3374-3378.

[9] R. Zhu, W. Chen, T.V. Shapley, M. Molinari, F. Ge, S.C. Parker, Environmental Science \& Technology 45 (2011) 6504-6510.

[10] Y. Park, G.A. Ayoko, R.L. Frost, Journal of Colloid and Interface Science 354 (2011) 292-305.

[11] Y.-H. Shen, Chemosphere 44 (2001) 989-995.

[12] G.W. Beall, M. Goss, Applied Clay Science 27 (2004) 179-186.

[13] R. Guegan, Soft Matter 9 (2013) 10913-10920.

[14] L.B. de Paiva, A.R. Morales, F.R. Valenzuela Díaz, Applied Clay Science 42 (2008) 8-24.

[15] Y. Deng, J. Dixon, G.N. White, Colloid and Polymer Science 284 (2006) 347-356.

[16] Y.D. Deng, J.B.; White, G.N., Clays and Clay Minerals 51 (2003) 150-161.

[17] R. Guégan, Langmuir 26 (2010) 19175-19180.

[18] R. Guégan, M. Gautier, J.-M. Beny, F. Muller, Clays and Clay Minerals 57 (2009) 502-509.

[19] S. Balme, R. Guegan, J.-M. Janot, M. Jaber, M. Lepoitevin, P. Dejardin, X. Bourrat, M. MotelicaHeino, Soft Matter 9 (2013) 3188-3196.

[20] R. Guégan, Journal of Colloid and Interface Science 358 (2011) 485-490.

[21] M. Gautier, F. Muller, L. Le Forestier, J.M. Beny, R. Guegan, Applied Clay Science 49 (2010) 247 254.

[22] A. Cerato, A. Lutenegger, Geotechnical Testing Journa 25 (2002) 1-7.

[23] M.D. LeVan, T. Vermeulen, The Journal of Physical Chemistry 85 (1981) 3247-3250.

[24] A.S. Ozcan, B. Erdem, A. Ozcan, Colloids and Surfaces A: Physicochemical and Engineering Aspects 266 (2005) 73-81.

[25] M.M. Dubinin, L.V. Radushkevich, Proc. Acad. Sci. Phys. Chem. Sec. (1947) 331.

[26] J.P. Hobson, The Journal of Physical Chemistry 73 (1969) 2720-2727. 
[27] M.S. Onyango, Y. Kojima, O. Aoyi, E.C. Bernardo, H. Matsuda, Journal of Colloid and Interface Science 279 (2004) 341-350.

[28] W.T. Tsai, C.W. Lai, K.J. Hsien, Journal of Colloid and Interface Science 263 (2003) 29-34.

[29] G. Rytwo, S. Nir, L. Margulies, Soil Sci. Soc. Am. J. 60 (1996) 601-610.

[30] G. Rytwo, D. Tropp, C. Serban, Applied Clay Science 20 (2002) 273-282.

[31] T. Nakamura, N. Kawasaki, T. Tamura, S. Tanada, Bulletin of Environmental Contamination and Toxicology 64 (2000) 377-382.

[32] Y. Seki, K. Yurdakoç, Journal of Colloid and Interface Science 287 (2005) 1-5.

[33] F.H. Crocker, W.F. Guerin, S.A. Boyd, Environmental Science \& Technology 29 (1995) 2953-2958.

[34] P. Malakul, K.R. Srinivasan, H.Y. Wang, Industrial \& Engineering Chemistry Research 37 (1998) 4296-4301.

[35] G. Alther, Waste Management 22 (2002) 507-513.

[36] S.-M. Koh, J.B. Dixon, Applied Clay Science 18 (2001) 111-122.

[37] V.A. Oyanedel-Craver, M. Fuller, J.A. Smith, Journal of Colloid and Interface Science 309 (2007) 485492.

[38] A.Z. Redding, S.E. Burns, R.T. Upson, E.F. Anderson, Journal of Colloid and Interface Science 250 (2002) 261-264.

[39] J. Smith, P. Jaffé, Journal of Environmental Engineering 120 (1994) 1559-1577.

[40] M.t. Julinova, R. Slavek, Journal of Environmental Management 94 (2012) 13-24.

[41] F. Wang, J. Yao, K. Sun, B. Xing, Environmental Science \& Technology 44 (2010) 6985-6991.

[42] N. Adhoum, L. Monser, Separation and Purification Technology 38 (2004) 233-239.

[43] X.-K. Zhao, G.-P. Yang, Y.-J. Wang, Water, Air, and Soil Pollution 157 (2004) 179-192.

[44] K.F. Sullivan, E.L. Atlas, C.S. Giam, Environmental Science \& Technology 16 (1982) 428-432.

[45] I.C. Bourg, G. Sposito, A.C.M. Bourg, Journal of Colloid and Interface Science 312 (2007) 297-310. 